\title{
A escrita colaborativa e as novas tecnologias: relato de experiência
}

\author{
The collaborative writing and new technologies: experience report
}

Sandro Luis da Silva*

\begin{abstract}
Resumo: Este texto trata da prática de produção textual do gênero artigo de opinião, na disciplina Comunicação e Expressão em um curso de formação inicial do tecnólogo. O objeto de análise são textos produzidos por alunos do segundo semestre do curso de Tecnologia em Análise de Sistema e Tecnologia da Informação em uma universidade pública no interior do Estado de São Paulo. O gênero escolhido para o desenvolvimento da atividade foi o artigo de opinião. Procurou-se associar a escrita de texto aos recursos da tecnologia, em especial os contidos no link "revisão" do Office 2007: "novo comentário" e "controlar alterações". A análise da atividade pautou-se, sobretudo, nos estudos de Schneuwly \& Dolz (2004) e Dionísio, Machado \& Bezerra (2005) e Garcia (2001), quanto ao gênero textual e no trabalho com novas tecnologias desenvolvido por Araújo \& Biasi Rodrigues (2005), Ribeiro (2012) e Pinheiro (2012). Constatou-se que a utilização dessas ferramentas permite uma dialogicidade entre os pares na sala de aula, caracterizando um trabalho colaborativo em relação à produção textual.
\end{abstract}

Palavras-chave: Gênero Textual; Office 2007; Produção Textual.

\begin{abstract}
This paper reports on the writing of opinion article exercised in the discipline Communication and Expression in an initial training course designed for Technologists. The objects of analysis are texts produced by students in the second semester of Technology in System Analysis and Information Technology at a public University in São Paulo. The genre chosen for the development of the activity was the opinion article. We sought to associate the written text to technology resources, in particular those contained in the link "review" of Office 2007: "new comment" and "track changes". The activity analysis was based mainly on studies of Schneuwly \& Dolz (2004) and Dionisio, Machado \& Bezerra (2005) and Garcia (2001), the text genre and working with new technologies developed by Araújo Rodrigues \& Biasi (2005), Ribeiro (2012) and Pinheiro (2012). It was found that the use of these tools allows dialogicity among peers in the classroom, featuring a collaborative work in relation to textual production
\end{abstract}

Keywords: Textual Genre; Office 2007; Textual Production.

\section{Considerações Iniciais}

Não há dúvidas de que o processo educacional precisa preparar o aluno para valorizar aspectos que o destaquem como cidadão consciente de sua realidade e, num mercado de trabalho cada vez mais competitivo, leva-lo a desenvolver as habilidades necessárias para que ele tenha competência para realizar suas atividades profissionais. Nas palavras de Rios (2001, p. 52), “O ensino não é, portanto, um movimento de transmissão que termina quando a coisa que se transmite é recebida, mas o começo do cultivo de uma mente de forma que o que foi

\footnotetext{
* Doutor em Língua Portuguesa pela Pontifícia Universidade Católica de São Paulo. Professor Adjunto de Língua Portuguesa e Ensino na Universidade Federal de São Paulo, campus Guarulhos.
} 
semeado crescerá". É essencial que, no ensino-aprendizagem, a prática educativa proporcione as condições necessárias para que o aluno se perceba como um sujeito inserido conscientemente na sociedade e que consiga socializar-se, assim como ultrapassar os limites da reprodução cultural e social do conhecimento, (re)criando-o. Infelizmente, isso não tem acontecido em todas as escolas brasileiras, apesar de todas as tentativas realizadas, seja por parte de órgãos públicos, direção e/ou prática docente, ainda permanece numa escola com uma visão bancária, como ensinava Paulo Freire, num ensino marcadamente tradicional, em que o professor é o centro do processo.

O docente em um curso superior, por exemplo, precisa criar estratégias que levem os alunos a "preencher" as lacunas que ficam no processo de escolarização da educação básica, a fim de que se possa formar um profissional com competência para o exercício das atividades profissionais. E, dentre as várias competências, a comunicativa, em que o aluno seja capaz de organizar o texto, linguística, temática e pragmaticamente, a fim de atender às expectativas de seu leitor/ouvinte.

Nesse sentido, cabem reflexões sobre as questões ligadas à leitura e à escrita, independentemente da área de formação profissional. Ainda que se tenha claro que a aquisição da leitura e a da escrita se realizam por processos distintos, pois envolvem habilidades diferenciadas, também é indubitável que uma influencia a outra. A prática costumeira da leitura de textos nos diferentes gêneros não só enriquece o vocabulário, como também possibilita a assimilação de estruturas frasais que são reutilizadas quando da produção de textos orais ou escritos, além de conduzir 0 leitor a construir as mais diversas imagens a partir do texto produzido, construindo sentidos para o discurso do texto. Ele é capaz de (res)significar o mundo em que está inserido. Mas isso só é possível quando a prática textual - produção e leitura - se torna significativa num dado contexto, no caso, no universitário.

Dentro do novo cenário educacional, a utilização de recursos tecnológicos no processo de ensino-aprendizagem não pode significar uma simples transformação do papel em tela. A incorporação dos avanços tecnológicos, com certeza, interfere no dia a dia dos cidadãos, exigindo o domínio de novos códigos, os quais se constituem cada vez mais operacionais pela tecnologia. É preciso ressaltar que com o advento da $\mathrm{Web} 2.0$, abrem-se possibilidades para a ampliação de práticas comunicativas, por meio das quais as pessoas interagem com seus pares, numa perspectiva diferente daquela categoria tradicional de autor/leitor, por exemplo. 
Diante dessas considerações, este texto tem por objetivo socializar um relato de experiência a partir de uma atividade de produção escrita com alunos do segundo semestre do curso de Tecnologia em Análise de Sistema e Tecnologia da Informação (ASTI) de uma Instituição Pública no Interior de São Paulo. Procura-se evidenciar como o uso da tecnologia, em especial o recurso do MS Word 2003, auxilia o aluno a interagir com seus pares e apreender alguns mecanismos linguísticos necessários para a elaboração de texto, mais especificamente no gênero artigo de opinião.

Assim, o intuito deste artigo é, a partir da socialização dessa experiência em aula de produção textual, refletir sobre as possibilidades do uso das novas tecnologias na escrita e suas repercussões na formação acadêmica. Para atingir esse propósito, o texto está dividido em três partes: a primeira, denominada "Um pouco de teoria", em que apresentamos uma discussão sobre as novas tecnologias e os gêneros discursivos. Em seguida, trazemos o contexto da pesquisa e a análise dos dados que nortearam este estudo. Por fim, fazemos algumas considerações sobre os pontos levantados no artigo.

\section{Um pouco de teoria}

A escrita "é algo tão importante na história que, para alguns, só existe história quando existe escrita" (Neves, 2003, p. 108). Assim, quando pensamos na escrita, podemos voltar aos fenícios e sumérios, aos gregos e romanos. E, com o passar do tempo, ela sofre impactos da invenção de diferentes materiais (argila, papiro, papel, tela, dentre vários outros), por meio dos quais se registra o texto, possibilitando que leitores de diferentes tempos e lugares possam ter acesso ao que foi produzido.

A escrita, como objeto social, é uma conquista da humanidade; ela é um grande avanço para todas as formas de comunicação anteriormente produzidas; representa a memória e a possibilidade da autoria, do pensamento, do consenso, da divergência, da diferença e da pluralidade de ideias. A escrita é uma ferramenta, uma representação de humanidade e, na escola e na sociedade, um bem indispensável.

A partir disso, é possível considerar que

$\mathrm{O}$ escrever que imprime significância à escrita; mas, antes necessitou o homem descobrir que os traços depositados em algum suporte material podem sinalizar para algo outro que eles mesmos, para uma ação humana reconhecível nas marcas que deixou após si (MARQUES, 1997, p. 41). 
A elaboração de um texto exige do sujeito - produtor (enunciador) - uma reflexão do contexto em que está inserido e o do enunciado, para que possa obter a resposta esperada e promover a interação com seu interlocutor, objetivo primeiro da comunicação. O domínio da tecnologia da escrita, na atualidade, está relacionado ao domínio de várias estratégias de escrita e, consequentemente, de interação social.

É pressuposto, neste texto, que a linguagem é uma construção social, em que dialogia e interação se constituem como seus elementos fundamentais. Considera-se, ainda, que a compreensão do domínio da própria autonomia discursiva também é construída na interação social que se realiza entre os interlocutores numa situação enunciativa,

Por meio da escrita, abre-se, no processo de ensino-aprendizagem, uma possibilidade para levar o aluno a vislumbrar a adequação de seu texto ao gênero solicitado, aos padrões exigidos pelo gênero textual, enfim, proporcionar ao educando a oportunidade de perceber a função social do texto, sem desprezar a estrutura e os mecanismos linguísticos necessários para a interação com o leitor do texto, explicitando a intenção textual.

Para Marcuschi, "é impossível se comunicar verbalmente a não ser por algum gênero, assim como é impossível se comunicar verbalmente a não ser por algum texto" (2005, p. 22). Os gêneros apresentam características sócio-comunicativas definidas por conteúdos, propriedades funcionais, estilo e composição. São essencialmente flexíveis e variáveis. Assim como a língua varia, os gêneros também variam, adaptam-se, renovam-se e multiplicam-se.

Para Bazerman (2006), gêneros são o que as pessoas reconhecem como gênero a cada momento do tempo; são rotinas sociais do dia a dia do ser humano. Para ele, os gêneros são fatos sociais e não apenas fatos linguísticos como tal, já que são considerados como parte constitutiva da sociedade. $\mathrm{O}$ autor ainda defende o postulado de que os gêneros textuais são frames ${ }^{l}$ para a ação social, e moldam os pensamentos que formamos e as comunicações por meio das quais interagimos. Eles constituem os lugares para onde nos dirigimos com o intuito de criar ações comunicativas inteligíveis uns com os outros (2006, p. 23). Assim, eles promovem a interação e enriquecem a vida do sujeito e, nesse sentido, tornam-se ambiente concreto para a aprendizagem em Língua Portuguesa, pois permitem ao interlocutor expressar o que já conhece e aproximar-se daquilo que objetiva descobrir.

\footnotetext{
${ }^{1}$ Frames (palavra do inglês que significa quadros, molduras) (FÁVERO, 2004, p. 63), nos limites deste trabalho, correspondem a modelos cognitivos globais, elementos de conhecimento que "emolduram" a constituição de um texto e que são ativados por sua leitura, e contêm o conhecimento comum sobre um conceito primário (geralmente situações estereotipadas).
} 
Bronckart, por sua vez, afirma: "conhecer um gênero de texto também é conhecer suas condições de uso, sua pertinência, sua eficácia ou, de forma mais geral, sua adequação em relação às características desse contexto social" (2003, p. 48). Como decorrência, pode-se afirmar que a representação de mundo e a possibilidade de interação entre os sujeitos de uma sociedade, ações possíveis pela linguagem, estão intrínsecas na concepção de gênero textual.

De acordo com Schneuwly e Dolz (2004), o gênero textual caracteriza-se como o meio de articular práticas sociais e objetos escolares, particularmente no que diz respeito ao ensino da produção e leitura de textos. Numa visão sociointeracionista, o gênero possibilita diversas práticas de linguagem, uma vez que correspondem a diferentes contextos e exígem óperações linguísticas que caracterizem determinada situação de comunicação.

Nessa concepção sociointeracional, escritor e leitor são vistos como construtores sociais, sujeitos ativos que dialogicamente se constroem e são construídos no texto. Dessa forma, a produção textual escrita caracteriza-se por uma atividade que demanda da parte de quem escreve a utilização de estratégias que motivem o conhecimento prévio, a seleção, a organização e o desenvolvimento de ideias, garantindo a progressão temática. A persuasão também é um elemento que precisa ser considerado ao escrever um texto; o enunciador precisa fazer-se verdadeiro em seu texto; é preciso promover um efeito de verdade naquilo que é expresso em um gênero textual.

Levando-se em consideração o novo cenário que se configura em relação à tecnologia da informação, sobretudo nos anos 90 do século XX, não há como a escola - a básica e/ou a superior - ignorar as novas tecnologias como uma estratégia no processo de ensinoaprendizagem.

De acordo com Vieira (2005), o uso da tecnologia para ler, escrever e divulgar informações mudou de maneira significativa o processo de leitura e de escrita nos diferentes gêneros textuais. Nas palavras da autora,

O uso da tecnologia digital para ler, escrever e divulgar informações transformou radicalmente a natureza da comunicação escrita e o letramento convencional, introduzindo novos gêneros textuais, práticas discursivas e estabelecendo um novo paradigma nas ciências da linguagem (2005, p. 19).

É preciso lembrar que as novas tecnologias não apagam as tecnologias existentes, tampouco solucionam as dificuldades encontradas no processo de escrita. Elas surgem para facilitar o processo de interação entre os indivíduos, para proporcionar novas possibilidades de 
escrita. Como afirma Ribeiro (2012, p. 29), "as tecnologias não precisam ser encaradas como ameaças, mas como novos meios de fazer, de propor e, por que não, de seduzir, tanto alunos quanto professor".

As aulas de língua materna não podem deixar de desenvolver nos alunos as habilidades de leitura e escrita para o mundo digital. Faz-se necessário que os alunos sejam capazes de escrever/ler usando novos dispositivos tecnológicos que estão presentes na sociedade.

O uso dessa tecnologia no processo de ensino-aprendizagem constitui-se, assim, em uma possível estratégia que aproxima o espaço da sala de aula com o mundo ao qual o aluno pertence. Não há como pensar em Educação, em (re)construção de valores, em transformações, em formações ideológicas, sem vislumbrar caminhos que promovam a interação entre escola e realidade, e as novas tecnologias podem facilitar esse percurso. Ratificamos que, uma vez não inserida neste novo contexto, a escola acaba por se distanciar da realidade em que os sujeitos estão inseridos.

Em uma aula de produção de texto, várias são as possibilidades de escolha do gênero com que se pode desenvolver uma determinada atividade, como, por exemplo, o artigo de opinião, que, segundo Garcia (2001), configura-se em um gênero em que a dialogicidade e alteridade se evidenciam no processo de produção: não é possível escrever um texto neste gênero sem se colocar no lugar do Outro, antecipando suas posições para poder refutá-las negociando ou não com ele - na direção de influenciá-lo e de transformar sua opinião, seus valores.

$\mathrm{O}$ artigo de opinião pertence à esfera jornalística, o qual traz alguns aspectos comuns com outros gêneros jornalísticos, como, por exemplo, a interação autor/leitor, que não acontece ao mesmo tempo e no mesmo espaço; não ocorre de "pessoa para pessoa", mas há uma mediação ideológica da esfera jornalística; é publicado com certa periodicidade e uma validade prevista (RODRIGUES, 2005).

Éimportante lembrar que ocorre uma sistematização quanto à topografia deste gênero: situa-se na seção "Opinião" - elemento constitutivo do gênero, pois é o lugar da sua ancoragem ideológica dentro do universo temático do jornalismo. De acordo com Rodrigues $(2005$, p. 171),

Dividindo o espaço com outros gêneros na seção Opinião, o artigo se situa entre os gêneros que historicamente têm seu horizonte temático e axiológico orientado para a manifestação da expressão valorativa a respeito de acontecimentos sociais que são notícia jornalística. É um dos gêneros onde os 
participantes da interação reconhecem e assumem esse trabalho avaliativo do autor.

Em relação ao lugar social que representa, percebe-se a presença de articulistas da esfera política e da esfera da indústria, do comércio, enfim, das mais diversas esferas que se encontram na sociedade. O ethos discursivo do articulista se manifesta ideologicamente neste gênero, ancorando-se em posicionamentos de outras vozes para dar credibilidade a seu discurso.

Este gênero possibilita ao aluno colocar-se como sujeito ativo diante do mundo em que está inserido, posicionando-se a partir de um fato de seu cotidiano. Bräkling (2000) define o artigo de opinião como um gênero discursivo no qual se busca convencer o outro sobre determinada ideia, influenciando-o e transformando seus valores por meio da argumentação a favor de uma posição, e de refutação de possíveis opiniões divergentes. Para a autora, é um processo que prevê uma operação constante de sustentação das afirmações, realizada por meio da apresentação de dados consistentes (2000, p. 226-227). Como afirmamos, embora o produtor do artigo se constitua numa autoridade para o que é dito, muitas vezes ele busca outras vozes para a construção de seu ponto de vista. Apoia-se ainda nas evidências dos fatos que corroboram a validade do que diz. Para Citelli (2004), todo texto, em maior ou em menor grau, é persuasivo. Para ele, persuadir "é, sobretudo, a busca da adesão a uma tese, perspectiva, entendimento, conceito etc, evidenciado a partir de um ponto de vista que deseja convencer alguém ou um auditório sobre a validade do que se anuncia” (p. 14).

Nessa mesma direção, Kaufman e Rodríguez (1995) afirmam que o artigo de opinião possui relação direta comas estratégias discursivas usadas para persuadir o leitor e não só com a pertinência dos argumentos apresentados. As autoras mencionam estratégias que podem ser usadas para fundamentar os argumentos: acusações claras aos oponentes, insinuações, digressões, apelações à sensibilidade ou tomada de distância através das construções impessoais para dar objetividade e consenso à análise desenvolvida, uso de recursos descritivos ou a especificação das diferentes fontes da informação (1995, p. 27). Todavia, é a expressão do posicionamento crítico do autor que garante consistência a este gênero discursivo.

Vale ressaltar que, em relação à temática deste gênero, como aponta Rodrigues (2005), refere-se a acontecimentos sociais próprios do universo da comunicação jornalística, mas que estão mediados ou se referem à esfera de atividades do autor. Há sempre uma motivação social que leva o enunciador a se posicionar no artigo, textualizando um acontecimento; é uma atitude responsiva a outros enunciados já ditos, na concepção bakhtiniana (1997). 


\section{Novas tecnologias: escrita em cooperação}

\section{O contexto da atividade}

Nesta parte do artigo, vamos contextualizar o estudo e desenvolver uma análise que contemple o uso das novas tecnologias na produção textual escrita, numa perspectiva do processo colaborativo. Trata-se de uma investigação sobre as possíveis contribuições das novas tecnologias na escrita, a partir da produção de um artigo de opinião, correção do artigo e reescrita do texto. No entanto, para este texto, o recorte é de analisar os dois primeiros procedimentos do desenvolvimento da atividade, como descreveremos mais adiante.

O exercício proposto - produção, revisão e reescrita de texto- conta com o apoio digital do Word e dos recursos de alterações controladas e de auto-texto do MSWord, o qual serviu para a orientação redacional dos estudantes e, ainda, do correio eletrônico (email), suporte utilizado para socializar os textos produzidos entre os pares e professor.

Os sujeitos que participaram desta atividade são alunos do segundo semestre do curso de Tecnologia em Análise da Informação (ASTI). A mạioria veio da escola pública e, segundo eles, na formação básica ainda há muita deficiência em relação ao desenvolvimento de atividades de leitura e de produção textual. Para esses alunos, as dificuldades com a língua ainda constituem a barreira para uma elaboração de texto - tanto oral quanto escrito. Deve-se acrescentar a isso o fato de terem um repertório de leitura muito restrito. Quando leem, eles se limitam a textos da área de atuação, ou seja, informática.

A atividade foi dividida em quatro partes: primeiramente, em sala de aula, o professor projetou o vídeo "Help Desk Top" (www.youtube.com), para a turma e, após exibição, abriu espaço para discussão. O filme, que durou aproximadamente 3 minutos, aborda questões relacionadas à necessidade de que as pessoas têm de serem ajudadas sempre que surge algo novo, inesperado, no caso, uma tecnologia - o livro em papel. Fica explicitado no filme que o "medo" e a insegurança causam inquietações e provocações no comportamento humano, interferindo nas relações sociais.

A segunda parte da atividade consistiu na escrita do artigo de opinião. Em casa, os alunos tiveram quinze dias para a escrita do texto, cujo gênero - características, estruturais e temáticas - já havia sido estudado em aulas anteriores. O professor alertou os alunos para a necessidade de explicitar uma tese, a qual deveria ser defendida por meio de evidências exemplos do cotidiano, discurso de autoridade, enfim, aqueles que corroborassem para 
persuadir o leitor. O tema, tendo em vista o vídeo apresentado, deveria envolver a relação das novas tecnologias na sociedade contemporânea.

A etapa seguinte foi o envio, por email, do texto a um colega, que exerceria a função de leitor/revisor. O docente orientou os alunos para que fossem feitos comentários pertinentes ao texto, sem perder de vista o estudo que fora feito sobre o gênero em questão. O leitor/revisor deveria devolver o texto ao autor, através do mesmo suporte, com cópia para o professor. Acreditamos que o suporte email constitui-se em uma ferramenta importante para o trabalho colaborativo, como mediadora no processo de ensino-aprendizagem da escrita. Assim, nesta etapa, tentou-se promover uma atividade de construção colaborativa de escrita pelos sujeitos envolvidos.

O leitor/revisor teve, ainda, a oportunidade de tecer um comentário geral sobre o texto lido, evidenciando a impressão que o texto lhe causou, as possibilidades discursivas que estariam presentes no texto, o grau de persuasão que o artigo apresentava.

Por último, realizou-se, entre professor e alunos, a discussão das observações feitas pelos pares e dos pontos positivos e negativos da atividade, para que fosse processada uma reescrita dos textos e, posteriormente, a avaliação do professor e a auto-avaliação.

Na verdade, a intenção da atividade era a de produzir um texto para que o aluno tivesse, posteriormente, a oportunidade de reescrevê-lo; o professor faria as intervenções necessárias, visando ao aperfeiçoamento da comunicação escrita. Não tínhamos a intenção de avaliar o comentário e a avaliação feitos pelos colegas e sim mostrar que, por meio de recursos das novas tecnologias, é possível interagir com os colegas, repensar e reescrever um texto.

\section{Análise do corpus}

Para este estudo, dos vinte e oito textos produzidos, foram escolhidos aleatoriamente quatro fragmentos dos artigos de opinião para mostrar como o apoio digital dos recursos de alterações controladas e de auto-texto do MSWord favorecem a intersecção entre produção textual e novas tecnologias, no processo ensino-aprendizagem. E, ainda, evidenciar como o professor pode se valer dessa estratégia para tornar as novas tecnologias uma ferramenta eficaz na produção escrita, em especial, levando o Outro a ler o texto de seu par.

A fim de ilustrar a correção e os comentários feitos pelos alunos, seguem alguns exemplos que demonstram o funcionamento e a utilização dos recursos do Word na atividade proposta: 
Figura 1

Observa-se que, por meio dos recursos oferecidos pela tecnologia digital, o aluno faz dois comentários em relação à estrutura, sem considerar o aspecto temático, as características do gênero artigo de opinião, discutidas anteriormente. Na verdade, pode-se inferir que o leitor/revisor evidencia a importância que ele dá para os aspectos gramaticais, sem considerar que, muitas vezes, para o gênero em questão, a argumentação é muito mais persuasiva do que a estrutura em si. Ele apenas apontou o erro, sem comentar ou fazer qualquer sugestão para correção, tampouco menciona questões relacionadas ao conteúdo, conforme havia combinado durante a proposta da atividade. Ele não faz menção à coerência que está comprometida no texto pelo mau uso dos conectivos, os quais estabelecem relação lógica entre as orações. Vale lembrar que as questões relacionadas à coesão por meio de conectivos já haviam sido trabalhadas em aula. O aluno poderia ter utilizado dessa ferramenta para comentar com mais competência e, assim, colaborado com maior pertinência com o colega em relação à produção textual. Ao propor a atividade, o professor, se tiver por objetivo examinar a avaliação que os colegas fazem dos textos de seus pares, é preciso chamar a atenção para este objetivo. Como apontamos anteriormente, neste momento, o objetivo era oportunizar o uso dos recursos do Word na escrita de um texto.

Outro exemplo:

Com tantas mudanças e evoluções tecnológicas, é comum um usuário leigo de informática não saber como proceder a novos procedimentos. Visando melhores práticas e padronização de atendimento, empresas pressionadas pela concorrência, criam novos métodos de suporte, resultando em deixar seu cliente sem base de conhecimento.
[S1] Comentário: É PROCEDER A MESMO? [S2] Comentário: REGÊNCIA VERBAL Formatado: Fonte: (Padrão) Times New Roman, 12 pt, Realce Formatado: Fonte: (Padrão) Times New Roman, 12 pt, Realce

Figura 2

Constata-se que o leitor/revisor, assim como no exemplo anterior, também se ateve à utilização da ferramenta do "comentário" para fazer a correção gramatical do texto e à questão da formatação do texto. No exemplo acima, leitor ainda utilizou o recurso do "realce" para 
chamar a atenção do autor do texto. Mais uma vez, como ocorreu na maioria dos comentários, o olhar recai somente nos aspectos estruturais do texto, sem relevar a questão temática. Não houve preocupação com outros elementos da textualidade, como, por exemplo, a coerência. Esse fato colocou-nos a refletir sobre a importância da orientação que o professor precisa fazer para que a atividade possa ser aproveitada ao máximo, quando proposta.

Outro aspecto a ser observado é quanto ao parágrafo, que é constituído por dois períodos isolados, sem estabelecer uma relação direta entre eles, o que enfraquece a questão argumentativa, que é tão exigida em um artigo de opinião. O produtor do texto, considerando o contexto global, definido pelas estruturas sociais, políticas, históricas e culturais, nos remete também à ideia de que hoje há uma exigência muito grande do mercado em criar estratégias, suportes que, de certa forma, faz com que o Outro não entenda perfeitamente o que de fato ocorre. Lança a ideia, mas não argumenta. E este fato não foi observado/comentado pelo leitor/revisor e, como dissemos, porque os alunos não foram orientados para este fim. A princípio, pediu apenas que se fizessem comentários, mas sem explicitar a natureza que deles.

Constatamos que o aluno/revisor tem a preocupação em observar as questões relacionadas à norma culta e, ao fazer um comentário, ele acaba por desviar da norma culta da língua; registra seus comentários com marcas da oralidade, como, por exemplo, "pra”. Neste sentido, há uma contradição discursiva. Isto também pode ser objeto de reflexão para professor e alunos, em relação à escrita de um texto, uma vez que, naquele momento, os alunos deveriam se colocar com distanciamento entre o texto do colega, já que exercia a função de leitor/revisor, o que demandaria uma formalidade linguística.

No parágrafo abaixo, o leitor/revisor valeu-se do comentário e do realce para identificar erros gramaticais. Ele foi um dos alunos da turma que se atentou para as questões relacionadas ao conteúdo e à própria estratégia da argumentação pedida pelo gênero. Observamos que o leitor/corretor faz, inclusive, comentários no próprio corpo do texto.

Existem vários fatores que causam o gap semântico, entre eles[QUAIS???], considero como principal, a pressa que as pessoas têm em terminar de ouvir logo e "fazer acontecer" para comprovarem se aquilo que foi dito deu certo. Que a vida hoje em dia é muito corrida todos nós já sabemos, mas se parássemos para ouvir melhor e não mais, essa distância seria bem menor e o retrabalho poderia ser evitado, conseqüentemente a produtividade, tanto da empresa cliente quanto ta empresa fornecedora, aumentaria.

Formatado: Fonte: Times New Roman, 12 pt, Realce [S1] Comentário: NÃO ENTENDI [S2] Comentário: DIGITAÇÃO Formatado: Fonte: Times New Roman, 12 pt, Realce [S3] Comentário: $E$ os argumentos? Como vc justifica?

Figura 3 
Embora não tenha sido orientado para a observação do conteúdo, o aluno consegue perceber que há necessidade de articulação do conteúdo para que se atinja o objetivo pretendido e, de fato, o leitor seja persuadido.

A proposta de uso desta ferramenta de apoio para a "leitura" e "correção" do texto do colega permite ao aluno apropriar-se de mecanismos que o levem à reflexão sobre a escrita do outro e da própria escrita. No exemplo acima, a ferramenta pode trazer subsídios que permitiram ao aluno-corretor refletir sobre a construção textual de seu par e sugerir novos ajustes no texto, ou seja, revisão e re-escrita.

No exemplo a seguir, o leitor assinalou com realce os erros encontrados no texto do colega, sem evidenciar em que consistia o desvio apontado. No entanto, ateve-se às questões dos argumentos, sugerindo ao colega que aprofundasse a argumentação, a fim de tornar o texto mais persuasivo. Podemos inferir que esse fato, dentre as várias possibilidades, leva o autor a refletir sobre a própria escrita:

Porem, o serviço nem sempre é tão ágil, por exemplo, quando é solicitado por muitos ao mesmo tempo, pode acarretar do cliente cair em uma fila de espera e ter que aguardar por tempo indeterminado, um problema que pode ser resolvido se os usuários do produto fizessem uso do manual para tirar algumas duvidas básicas sobre $o$ equipamento, com isso economizando do próprio tempo e conseqüentemente diminuindo custos para a equipe de helpdesk. Porem uma das causas que faz o usuário recorrer ao Helpdesk é a linguagem técnica e complicada dos manuais. Por este motivo é fundamental que as empresas criem guias mais concisos e de fácil entendimento.
Formatado: Fonte: (Padrão) Times New Roman, 12 pt, Realce

Formatado: Fonte: (Padrão) Times New Roman, 12 pt, Realce Formatado: Fonte: (Padrão) Times New Roman, 12 pt, Realce Formatado: Fonte: (Padrão) Times New Roman, 12 pt, Realce Formatado: Fonte: (Padrão) Times New Roman, 12 pt, Realce Formatado: Fonte: (Padrão) Times New Roman, 12 pt, Realce Formatado: Fonte: (Padrão) Times New Roman, 12 pt, Realce

[S1] Comentário: Rever a estrutura da frase. Coesão comprometida Formatado: Fonte: (Padrão) Times New Roman, 12 pt, Realce [S2] Comentário: Há problemas de coerência... argumentos fracos.

Figura 4

É correto inferir que a atividade promoveu o desenvolvimento da escrita de um texto a partir da leitura do texto em situação de comunicação real, porque o aluno-corretor não é apenas leitor, mas também um avaliador da produção textual, o qual faz sugestão que vise ao aperfeiçoamento da escrita. Sem dúvida, os alunos foram obrigados a criar e/ou recorrer estratégias de leitura e de produção de texto que levassem seu par a vislumbrar novas possibilidades de (re)escrita.

De modo geral, os alunos ativeram-se aos desvios gramaticais, como exemplificam os fragmentos trazidos, deixando de apontar casos de incoerência e problemas com a articulação 
do conteúdo, assim como a carência de argumentos mais persuasivos. Podemos inferir que isso se constitui em um reflexo de correção que eles poderiam ter tido durante a escola básica, como eles mesmos apontaram em conversa posterior à devolutiva dos textos para os colegas pelos leitor/revisor, via email. Acrescente, ainda, a não orientação do professor em relação ao que desejaria, de fato, em relação aos comentários e à correção.

Como apontamos, a última etapa da atividade foi caracterizada pela escrita de um comentário geral sobre o artigo do colega. Os comentários se ativeram sobre o conteúdo apresentado e a estrutura vista em aula sobre o gênero, contrariando, de certa forma, a correção que fizeram no texto propriamente dito, ao utilizarem a ferramenta de revisão do Office 2007.

Vejamos três exemplos que ilustram isso:

Comentário do aluno D: O texto está bem escrito e descreve corretamente a realidade de alguns helpdesks. Os argumentos para amenizar os problemas são tangíveis e adequados ao assunto. O exemplo utilizado, da Apple como sendo uma empresa que fabrica produtos fáceis de serem utilizados é bem apropriado, uma vez que a empresa é realmente conhecida por esta qualidade. Como única ressalva, o autor poderia ter desenvolvido melhor o primeiro parágrafo, que ficou um pouco vago.

Comentários ao aluno C: $\mathrm{O}$ artigo está estruturado de modo que contextualiza o problema no primeiro parágrafo, nesse caso o gap semântico. Já no segundo parágrafo o autor cita exemplos do problema que o gap gera nas empresas que oferecem o serviço de help-desk e também mostra sua tese de que esse sério problema ainda vai trazer muitos problemas para os cliente e também para elas mesmas. Para sustentar o artigo, o autor oferece um argumento sobre a quantidade de textos relacionados à falta de entendimento que se encontram na internet. Para finalizar propõe uma solução no final do artigo, levando os leitores a refletir sobre o tema abordado.

Comentário do aluno B: O artigo aborda o assunto Suporte Técnico em TI no que diz respeito à metodologia de atendimento, focando especificamente nos resultados obtidos quando estas são adotadas. A contextualização foi pouco explorada, faltando talvez ambientar o leitor no conceito corporativo de suporte técnico, o que acaba não estabelecendo um bom gancho com a tese do artigo, prejudicando a coesão. A argumentação foi bem postada, utilizando de exemplos numéricos bem pesquisados e explicados para defender a tese da necessidade de um helpdesk bem estruturado para obter resultados. Porém a conclusão não permite estabelecer a posição crítica do autor sobre o assunto, já que há uma certa contradição nos dois últimos parágrafos. Portanto, o texto traz importantes informações sobre helpdesk, é bem argumentado, mas não tem a mesma qualidade em relação a coesão e contextualização.

Os três comentários referem-se à estrutura do parágrafo argumentativo e ao conteúdo solicitado na proposta da atividade. Os alunos conseguem recuperar, por meio da memória discursiva, os pontos que foram discutidos na parte teórica da aula, ou seja, as características 
do gênero estudado. Eles chamam a atenção para o fato de que as três partes do texto argumentativo precisam estar ligadas de forma coesa e coerente e, ainda, comentam a necessidade de evidências que ressaltem os argumentos, que defendam a tese trazida pelo produtor do artigo.

Outro ponto a ser observado é a questão da reflexão que o artigo precisa promover em seu leitor, por meio de um posicionamento crítico do autor a respeito do tema. Observou-se que na leitura e na correção do texto é dada a oportunidade do aluno (re)ver não só a estrutura do texto argumentativo e os mecanismos linguísticos, como também de olhar a escrita de um texto cujo tema foi também a ele proposto.

A atividade proposta demonstra que as novas tecnologias podem auxiliar o aluno não só na avaliação ao conteúdo desenvolvido pela disciplina de Comunicação e Expressão, como também promover reflexão e interação entre os pares, desenvolvendo/aprimorando a habilidade de comunicação interpessoal. A experiência evidenciou que, além do computador, outras multimídias podem favorecer o processo de ensino-aprendizagem da disciplina no curso de formação de tecnólogos, face à língua(gem) em uso nas mais diferentes situações enunciativas.

\section{Considerações Finais}

Cada vez que produzimos um texto escrito, criamos um novo enunciado para uma determinada circunstância. É por isso que o ato de escrever é considerado difícil, uma vez que temos de pensar em palavras novas, apropriadas e efetivas em um determinado texto, que se caracteriza como um evento interativo.

Sempre que escrevemos, produzimos o texto em um domínio discursivo identificável; procuramos mobilizar formas reconhecíveis para localizar nossa atividade; procuramos perceber possibilidades, formular intenções, na tentativa de fazer de nosso texto algo inteligível para nosso leitor.

É preciso que tenhamos estratégias que nos levem à produção de um texto eficaz. Para isso, necessitamos mobilizar nosso conhecimento enciclopédico e linguístico.

Ao resgatar, primeiramente, a concepção da Educação e sua finalidade, assim como os processos por que passou a escrita até a chegada da internet, especialmente no que diz respeito à interação social, procuramos entender como essas transformações implicaram novas possibilidades para a produção textual escrita no contexto universitário, mais especificamente no curso de Tecnologia da Informação. 
Propusemos a análise de uma atividade, a fim de evidenciar a importância que as novas tecnologias assumem em práticas de linguagem, oferecendo, inclusive, momento de construção colaborativa entre os alunos. Mesmo em se tratando de um recorte no processo como um todo, foi possível observar que as atividades elencadas para análise levam-nos a refletir sobre o trabalho docente e discente no processo de ensino-aprendizagem de língua materna, a partir do uso das novas tecnologias como ferramenta que podem auxiliar a construção de um conhecimento na disciplina Comunicação e Expressão no curso de Análise de Sistema e Tecnologia da Informação.

Esta atividade oportunizou ao aluno chances reais de recuperação de sua escrita, de sua identidade, de sua competência comunicativa, além de fornecer instrução gramatical diretamente ligada à língua em funcionamento, para auxiliar o aluno a aperfeiçoar seu texto e compreender os mecanismos linguísticos que tornam o texto coeso, coerente e significativo dentro do contexto em que está inserido.

A atividade levou os sujeitos do processo de ensino-aprendizagem - professor e aluno - a repensar sobre os problemas textuais apontados e comentados nas orientações dadas pelo professor e na leitura feita pelos pares. Ela possibilitou a recuperação de conhecimento prévio, de exercícios de linguagem, de (re)visão dos elementos essenciais para a articulação de um texto, além de fornecer a instrução gramatical diretamente na língua em funcionamento e da própria semântica, tendo em vista que visou, além de tudo, ao efeito de sentido das palavras num dado contexto. É chamada a atenção para a importância da precisão vocabular, da correção gramatical e do compromisso com a coerência e a coesão textuais no artigo de opinião.

Outro ponto bastante interessante na atividade e que cabe ser ressaltado aqui é a questão do gênero textual e as novas tecnologias. Quanto ao primeiro, é indiscutível que ele promove a possibilidade não só o autor exercitar a escrita, como também entrar em diálogo com diferentes textos para que possa articular adequadamente suas idéias e atingir a persuasão. Foi possível levar os alunos a perceber a necessidade de evidenciar fatos que fizessem com que o leitor aderisse as idéias contidas no texto.

Em relação às novas tecnologias, nesta atividade em especial, elas foram responsáveis pela interação entre os alunos/alunos, alunos/professor, provocando uma (re)significação para a produção textual. Elas possibilitaram ao educando vislumbrar caminhos por que ele pode percorrer unindo diferentes áreas do saber, no caso, Comunicação e Expressão e Tecnologias. 
Essa atividade procurou levar o aluno a compreender o modo de participação do Outro/interlocutor na (re)escrita do texto, a partir dos comentários que este faz sobre o texto de seu par. Ressalte-se, ainda, que a (re)escrita promove a oportunidade do autor explicitar sua competência comunicativa (KAUFMAN, 1995), com a intenção de dizer algo a alguém.

Destacamos, ainda, que ela promoveu a relação interpessoal entre alunos, pois, com a troca dos textos, via email, houve a oportunidade do grupo conhecer um pouco mais sobre seu par, e perceber que o ato de escrever constitui-se em uma atividade que traz dificuldades para todos aqueles que a tem como tarefa, seja acadêmica, seja profissional.

Foi possível inferir, a partir dos resultados deste trabalho desenvolvido, que há muitas relações entre os leitores e os textos, o que os leitores dizem sobre si e o que realmente sabem fazer. É preciso que seja propiciado aos alunos momentos de leitura e de escrita, utilizando diferentes estratégias e, dentre elas, aquelas oferecidas pelas novas tecnologias, inclusive.

Não acreditamos que a escrita não seja um dom, que é dado de presente ao indivíduo; ela deve ser compreendida como um trabalho, como uma execução que precisa ser desenvolvida com dedicação, esforços e conhecimento. Ela resulta de tentativas, escritas e reescritas. A nosso ver, o exercício relatado neste artigo põe em evidência essas características.

As novas tecnologias podem oferecer aos alunos diversas linguagens e variados recursos para que articulem seus textos de forma coesa, coerente, significativa para o propósito comunicacional que faz parte do cotidiano do ser humano.

Por meio desta atividade na aula de Comunicação e Expressão, é possível vislumbrar a superação da fragmentação do currículo, organizado em disciplinas. Houve uma tentativa de um olhar interdisciplinar em que dialogaram as questões relacionadas ao texto e o uso das novas tecnologias no processo de ensino-aprendizagem, abrindo caminhos para a construção de novos conhecimentos e de estratégias para esta construção.

Numa conversa informal, os alunos aprovaram a estratégia utilizada na produção e na leitura de textos; eles viram a oportunidade não só de escrever, como também de ler o texto do outro e fazer/receber sugestões para uma possível reescrita. Trata-se de uma forma bastante interessante para reverem ou adquirirem conhecimentos linguísticos necessários para a articulação do texto em língua portuguesa, valendo-se de um instrumento que utilizam no dia a dia profissional. 


\section{Referências bibliográficas}

BAKTHIN, M. "Os gêneros do discurso". In Estética da Criação Verbal. Trad. Maria Ermantina G. G. Pereira. São Paulo: Martins Fontes, 1997, p. 277-326.

BAZERMAN, C. Gênero, agência e escrita. HOFFNAGEL, Judit Chambliss e DIONÍSIO, Angela Paiva (Organizadoras). Tradução e Adaptação: HOFFNAGEL, Judit Chambliss. São Paulo: Cortez, 2006.

BRÄKLING, K. L. Trabalhando com artigo de opinião: re-visitando o eu no exercício da (re)significação da palavra do outro. In: ROJO, Roxane (Org.). A prática da linguagem em sala de aula: praticando os PCN. São Paulo: EDUC; Campinas, SP: Mercado de Letras, 2000, p. 221-247.

BRONCKART, J. Atividade de linguagem, textos e discursos: por um interacionismo sóciodiscursivo. Trad. Anna Maria Machado, Péricles Cunha. São Paulo: EDUC, 2003.

CITELLI, A. Linguagem e persuasão. São Paulo: Ática, 2004.

FÁVERO, L. L. Coesão e coerência textuais. 9. ed. São Paulo: Ática, 2004.

GARCIA, O. M. Comunicação em prosa moderna. Rio de Janeiro: FGV, 2001.

KAUFMAN, A. M. \& RODRÍGUEZ, M. H. Escola, leitura e produção de textos. Porto Alegre: Artmed Editora, 1995.

MARCUSCHI, L. A. Gêneros textuais: definição e funcionalidade in DIONISIO, A. P., MACHADO, A. R. \& BEZERRA, M. A. Gêneros textuais \& Ensino. Rio de Janeiro: Lucerna, 2005.

MARQUES, M. O. Escrever é preciso: o princípio da pesquisa. Ijuí: Unijuí, 1997.

NEVES, I. Ler e Escrever: Compromisso de todas as áreas. Porto Alegre: Editora da UFRGS, 2003.

PINHEIRO, P. A. "Práticas colaborativas de escrita por meio de ferramentas da internet ressignificando a produção textual no contexto escolar" in SIGNORINI, I. e FIAD, R. S. Ensino de língua - das reformas, das inquietações e dos desafios. Belo Horizonte: Editora da UFMG, 2012, p. 248-281

RIBEIRO, A. E. Novas tecnologias para ler e escrever - algumas ideias sobre ambientes e ferramentas digitais na sala de aula. Belo Horizonte, RHJ Editora, 2012.

RIOS, T. A. Compreender e ensinar - por uma docência da melhor qualidade. São Paulo: Cortez, 2001. 
RODRIGUES, R. H. "Os gêneros do discurso na perspectiva dialógica da linguagem: a abordagem de Bakhtin". In MEURER, J. L., BONINI, A. e MOTTA-ROTH, D. (orgs.). Gêneros - teorias, métodos, debates. São Paulo: Parábola, 2005, p. 152-183.

SCHNEUWLY, B. \& DOLZ, J. (org). Gêneros orais e escritos na escola. Campinas: Mercado de Letras, 2004.

VIEIRA, I. L. Tendências em Pesquisas em Gêneros Digitais: Focalizando a Relação Oralidade/Escrita in Araújo \& Biasi-Rodrigues. Interação na internet - novas formas de usar a linguagem. Rio de Janeiro: Lucerna, 2005, p. 19-38.

Artigo recebido em: 25.02.2013

Artigo aprovado em: 10.05.2013 